\title{
El vanguardismo modernizador y sus límites: La Sociedad de Fomento Fabril ante el proyecto económico de Jorge Alessandri, 1958-1962
}

\author{
Joaquín Fernández Abara ${ }^{1}$ \\ Margarita Goldflam Leiva ${ }^{2}$
}

Recibido: 29 de diciembre de 2017 - Aprobado: 23 de abril de 2018

\begin{abstract}
Resumen
El artículo analiza el papel que cumplió la Sociedad de Fomento Fabril ante el proyecto económico de Jorge Alessandri. Sostenemos que la dirigencia de la SOFOFA actuó con autonomía relativa respecto del grupo social que le dio origen, apoyando el proyecto de modernización industrial impulsado por la presidencia. La SOFOFA defendió dicho proyecto entre los industriales y ante la opinión pública, al mismo tiempo que actuó como instancia negociadora entre distintos sectores del empresariado y el gobierno, morigerando los efectos adversos para la industria de sus medidas económicas y promoviendo soluciones gradualistas que aseguraban la continuidad del proyecto. En este rol, logró contener las demandas de sectores del empresariado fabril que se veían afectados por las medidas estabilizadoras y aperturistas del gobierno y, especialmente, la exigencia de aumento de créditos. Sin embargo, la acumulación de demandas insatisfechas, sumadas al fracaso de las medidas estabilizadoras, aumentarían el descontento entre diversos sectores de los empresarios industriales, obligando a la directiva de la Sociedad a renunciar a su agenda modernizadora.
\end{abstract}

Palabras clave: empresarios industriales, gremios empresariales, modernización, política económica

Chileno. Ph.D. (c) en Historia, Universidad de Leiden, Países Bajos. Profesor Investigador, CIDOC-Escuela de Historia, Universidad Finis Terrae, Chile. E-Mail: jfernandez@uft.Cl

2 Chilena. Licenciada en Historia, Universidad Finis Terrae, Chile. Estudiante del Programa de Magíster en Historia, Pontificia Universidad Católica de Chile. E-Mail: mgoldflam@hotmail.com Este artículo es parte del Proyecto FONDECYT No1150819 "El itinerario del proyecto monetarista chileno (1952-1975)". Los autores agradecen la ayuda prestada por Rodrigo Mardones Modinger en el proceso de recolección de fuentes primarias. 


\title{
Modernizing avant-garde and its limits: The Society of Manufacturing Development in front of Jorge Alessandri's economical project, 1958-1962
}

\begin{abstract}
This article analyzes the role the Society of Manufacturing Development had for Jorge Alessandri's economical project. SOFOFA's (Society of Manufacturing Development) management acted with relative autonomy in relation to the founder social group supporting the project of industrial modernization conducted by the Presidency. SOFOFA defended that project among industrials and in front of public opinion, and at the same time it acted as a mediator among the different industrial sectors and the Government moderating the adverse effects of their economic measures in the industry and promoting gradual solutions that assured the continuity of the project. In this role, it could contain the demands of the manufacturing company areas affected by the governmental stabilizing and liberal measures, and especially the increasing demand for credits. However, the accumulation of unsatisfied demands added to the failure of the stabilizing measures would increase the discontent among diverse areas of industrial entrepreneurs pressed the management to forego the modernizing agenda.
\end{abstract}

Keywords: Industrial entrepreneurs, management union, modernization, economic policy.

\section{O vanguardismo modernizador e seus limites: A Sociedade de Fomento Fabril perante o projeto econômico de Jorge Alessandri, 1958-1962}

\begin{abstract}
Resumo
0 artigo analisa o papel que cumpriu a Sociedade de Fomento Fabril perante 0 projeto econômico de Jorge Alessandri. Sustemos que a liderança da SOFOFA atuou com autonomia relativa no que diz respeito ao grupo social que the deu origem, apoiando o projeto de modernização industrial impulsado pela presidência. A SOFOFA defendeu dito projeto entre os industriais e perante a opinião pública, ao mesmo tempo em que atuou como entidade negociadora entre diferentes setores do empresariado e o Governo, reduzindo os efeitos adversos para a indústria de suas medidas econômicas e promovendo soluções graduais que garantiam a continuidade do projeto. Nesse papel, conseguiu conter as demandas de setores do empresariado fabril que se viam afetados pelas medidas estabilizadoras e de abertura do governo e, especialmente, a exigência de aumento de créditos. No entanto, a acumulação de demandas insatisfeitas, somadas ao fracasso das medidas estabilizadoras, aumentariam o descontentamento entre diversos setores dos empresários industriais, obrigando à diretiva da Sociedade a renunciar a sua agenda modernizadora.
\end{abstract}

Palavras-chave: empresários industriais, grêmios empresariais, modernização, política econômica 


\section{Introducción}

En este artículo analizaremos la relación establecida entre la Sociedad de Fomento Fabril (SOFOFA), principal órgano de representación gremial de los empresarios industriales, y el gobierno de Jorge Alessandri Rodríguez. Específicamente, nos centraremos en la manera en que la SOFOFA enfrentó las políticas económicas de la administración Alessandri.

En consonancia con diversos trabajos que han estudiado el periodo, sostenemos que la llegada al poder de la administración Alessandri, implicó un "desafío" para los empresarios industriales. Esto en cuanto las políticas económicas del gobierno involucraban exigencias de modernización que los debían poner en condiciones de subsistir con menores niveles de protección estatal, a la vez que abrirse a una mayor competencia.

Consideramos necesario tener algunas prevenciones de carácter teórico, con consecuencias metodológicas para el estudio. En primer lugar, sostenemos que, si bien es necesario considerar a los empresarios industriales como un grupo con determinadas identidades e intereses, hay que tener en cuenta que sus organizaciones gremiales pueden desarrollar agendas propias, las que pueden diferenciarse, de manera relativa, de las del grupo social que le dio origen. En este sentido, es imprescindible tener en cuenta el rol de las dirigencias empresariales en cuanto "actores políticos", asumiendo que su actuación no necesariamente tiene que ser considerada como completamente representativa de las conductas del grupo social al que pertenecen (Beltran, 2012: 88). De esta manera, al análisis de los "intereses" añadimos la influencia de las contingencias políticas y los elementos ideológico-intelectuales (Hoschild, 2006). En segundo lugar, es forzoso sostener que al interior de los empresarios industriales como grupo social pueden existir intereses que diverjan, lo que implica evitar considerarlos como un colectivo siempre homogéneo, teniendo en cuenta la existencia en su interior de distintos "sectores".

Debemos señalar que diversos estudios que han abordado el tema (Stallings, 1978; Gómez Chamorro, 1983; Montero, 1997; Correa, 2005; Moulian, 2014) han tendido a analizar la conducta de los "industriales" a través de la actuación de los "gremios empresariales" que los representaban. ${ }^{3}$ Algunos estudios, como los de Marcelo Cavarozzi (1975 y 2017), han roto en parte esta tónica, enfatizando en las agendas específicas de los sectores que tomaron el control de la SOFOFA desde mediados de la década de 1950 y el rol mediador que cumplieron entre gran parte del empresariado

Para conocer las nuevas perspectivas en el estudio de la historia empresarial chilena, véase el libro de Llorca-Jaña y Barría (2017). 
y el gobierno de Jorge Alessandri. Por nuestra parte, teniendo en cuenta los aportes de dichos textos e inscribiéndonos en la línea desarrollada por Cavarozzi, pretendemos analizar a la Sociedad de Fomento Fabril como una organización que actúa con una autonomía relativa. Esta situación nos permite, además, tematizar las relaciones y las tensiones generadas entre esta y el empresariado que representaba. Con este fin, nos centraremos en los discursos y prácticas políticas desarrolladas por la directiva de la Sociedad en el periodo.

Consideramos que estudiar a la Sociedad de Fomento Fabril en la década de 1960 es de suma importancia para entender la historia política y económica de Chile en el siglo XX. Esto pues se trataba del principal gremio representativo de los empresarios industriales en un nivel nacional. Por lo demás, la SOFOFA había alcanzado un amplio grado de incidencia en las decisiones de política económica. De este modo, el estudio de sus posturas y sus pugnas internas permite comprender mejor y de manera más compleja los desafíos y alternativas vividas por el mundo empresarial y los sectores dominantes de la sociedad chilena en una etapa de aceleradas transformaciones, en que su hegemonía comenzó a verse seriamente amenazada. Más aún cuando consideramos que el periodo que abarca los años de fines de la década de 1950 e inicios de la 1960 fue la única ocasión en la época del "estado de compromiso" en que la derecha y la fuerzas empresariales pudieron ejercer una agenda de transformaciones desde el Gobierno.

Con el fin de desarrollar la investigación, hemos dividido el texto en cinco partes, siguiendo un orden cronológico. En una primera parte analizaremos la actitud asumida por la Sociedad de Fomento Fabril ante la llegada al poder del gobierno de Jorge Alessandri; en segundo lugar, analizaremos el papel que cumplió la Sociedad de Fomento Fabril como interlocutor entre el empresariado industrial y el gobierno en los años 1958, 1959 y 1960. En una tercera parte abordaremos las tensiones más relevantes aparecidas entre el empresariado industrial y el gobierno entre 1960 y 1961, enfatizando en cómo la Sociedad intentó manejarlas hasta llevar a un serio distanciamiento a fines de ese año. En la cuarta parte trataremos los últimos intentos de articulación sistemática entre la SOFOFA y el Gobierno en el segundo semestre de 1961. Finalmente, en una quinta parte, abordaremos el quiebre de las relaciones entre la SOFOFA y el gobierno y la pérdida de hegemonía del sector modernizador al interior de la Sociedad en el primer semestre del año 1962. Hemos privilegiado el periodo comprendido entre 1958 y 1961, en cuanto este representa el momento de vigencia del proyecto de gobierno original del alessandrismo. Nos centraremos en conocer el discurso público enarbolado por la sociedad, sus prácticas de negociación con el gobierno y con distintos sectores empresariales, y, hasta donde es posible, los debates y disidencias que generó en su interior. 
Con este fin, hemos revisado publicaciones institucionales de la Sociedad de Fomento Fabril, como la revista Industria y las memorias anuales. A la vez que hemos consultado un amplio arco de prensa, que nos permite contrastar la información brindada por las fuentes institucionales de la Sociedad. También hemos revisado documentación presente en el Archivo Jorge Alessandri Rodríguez, de la Sala Medina de la Biblioteca Nacional y en el Fondo Jorge Alessandri Rodríguez, del Archivo CIDOC de la Universidad Finis Terrae.

\section{El advenimiento del gobierno de Alessandri y las esperanzas de la directiva de la SOFOFA}

En el marco de una inserción publicada en el diario La Nación el 17 de noviembre de 1958, la que, sintomáticamente, se encontraba dirigida a empleados y obreros, la Sociedad de Fomento Fabril manifestó su complacencia con la ascensión al poder del presidente Jorge Alessandri Rodríguez:

"El aniversario de los 75 años de la fundación de la Sociedad de Fomento Fabril se celebra en el preciso momento en que un soplo vigoroso de esperanzas acompaña la ascensión en el poder de un nuevo gobernante salido de las propias filas de la industria. Que esta celebración fortifique el espíritu de unión entre los que de una u otra forma participan en el viril y duro esfuerzo industrial de Chile". (La Nación, 17-XI-1958: 13)

La llegada al poder de Jorge Alessandri coincidió con el aniversario número 75 de la Sociedad. Dicha instancia sirvió de escenario privilegiado para que la directiva de la SOFOFA hiciese un balance de su trayectoria y de la historia del sector industrial en Chile, enfatizando en el modo en que las políticas económicas de los gobiernos recientes habrían afectado a su sector. Del mismo modo, aprovechó la ocasión para plantear su apoyo al programa del nuevo gobierno y a la vez resaltar los desafíos que este debería enfrentar. Domingo Arteaga, presidente de la SOFOFA, sostuvo en un discurso en la "comida de clausura" de los festejos de aniversario, que:

"Deseamos los miembros de la Sociedad de Fomento Fabril cumplir con el destino industrial de Chile [...] Que se eliminen controles inútiles y mecanismos restrictivos paralizantes que no solo contribuyen a entorpecer la producción o la distribución. Nosotros cumpliremos la parte de esfuerzo y sacrificio para que en los próximos seis años Chile se ponga de pie y reanude la dura pero auspiciosa marcha de su historia". (El Diario Ilustrado, 23-XI-1958: 5)

Los planteamientos de Arteaga sintetizaban varios elementos importantes que definirían la actitud de la SOFOFA durante el periodo inicial del gobierno 
de Jorge Alessandri. Así daban a conocer en un claro mensaje a la opinión pública, dando continuidad al programa de política económica que la Sociedad venía defendiendo desde inicios de la década de 1950. En efecto, Arteaga recalcó que "este aniversario nos encuentra abocados a serios problemas, que venimos exponiendo desde hace ya tiempo [...] En la convención de 1953, con asistencia de 8000 industriales expusimos las realidades ante el gobierno de Ibáñez. No fuimos escuchados" (El Mercurio, 18-XI-1958: 15). No es de extrañar que, al abordar las actividades de celebración del aniversario de la Sociedad, el periódico Las Noticias de Última Hora, vinculado al Partido Socialista, titulara irónicamente la noticia diciendo que "Fomento Fabril apaga sus 75 'velas' con palos a Ibáñez y flores a Alessandri" (Las Noticias de Última Hora, 18-XI-1958: 4).

En consonancia con los planteamientos que la Sociedad venía elaborando y difundiendo desde comienzos de los años cincuenta, la SOFOFA defendía un modelo de desarrollo en que el Estado mantenía un importante rol en la protección, fomento y planificación del desarrollo industrial, a la vez que enarbolaba el ideal de "empresa privada en libre competencia". Este último concepto era entendido como la retirada del Estado de la propiedad y control de la producción industrial, la disminución de las regulaciones y los controles estatales, y la autonomización del Estado respecto a las crecientes demandas sociales de carácter redistributivo del periodo, especialmente del movimiento obrero. ${ }^{4}$ Arteaga fue enfático en su defensa del ideal de libre empresa y en sus afanes de evitar la cooptación de la política económica del Estado por parte de las demandas laborales y de agentes políticos receptivos a estas:

"Creemos, como el mismo lo ha señalado varias veces, que Chile requiere ante todo, y por sobre y por sobre todo, reafirmar los altos valores morales que ennoblecieron a su pasado, y extirpar, con rigidez portaliana, los malos hábitos que la politiquería ha introducido en la vida pública [...] Esperamos que cada vez que, a través de reajustes u otro tipo de beneficios, se requiera hacer justicia económica un grupo o sector determinado, ello no se efectúe a expensas del resto de la población, cometiendo una injusticia mayor, en extensión, que la que se pretende reparar [...] Paralelamente a esta labor previa de limpieza, desearíamos ver mayor liberalidad en el campo económico para que comience a actuar la más poderosa herramienta rectificadora del régimen de empresa privada, que es la competencia. Que se eliminen los controles inútiles y mecanismos restrictivos, paralizantes,

4 Para una síntesis descriptiva y un análisis del programa de política económica desarrollado al alero de la Sociedad de Fomento Fabril en la década de 1950, véase Fernández Abara y Goldflam (2016). 
que solo contribuyen a entorpecer la producción o la distribución". (El Mercurio, 22-XI-1958: 21)

Domingo Arteaga defendía el rol planificador del Estado y su importancia en las actividades de fomento, especialmente en el ámbito de las obras públicas, donde ejercería un efecto multiplicador en la producción industrial:

"Juzgamos útil alentar al gobierno en su propósito de iniciar rápidamente un plan habitacional capaz de poner en actividad al enorme sector industrial relacionado con la construcción, procurar trabajo a los que de él carecen, que ya son muchos, e ir resolviendo a la vez, el déficit endémico de viviendas populares. Una reactivación de las obras públicas que un estudio de prioridades señale como las más útiles y urgentes puede complementar el plan habitacional en muchos aspectos, sin mayor recargo de los presupuestos de la nación. La Sociedad de Fomento Fabril, por su parte, y sin que ello interfiera en los planes y proyectos de los industriales que la confianza en el nuevo jefe de Estado les alienta a revivir y poner luego en marcha, está empeñada, con la colaboración de la Corporación de Fomento, en formular un "plan de desarrollo industrial". Considerando lo limitado de los recursos materiales y humanos de que dispone Chile, no se puede cometer la torpeza de malgastarlos o utilizarlos con ineficiencias". (EI Mercurio, 22-XI-1958: 21)

Sin embargo, las palabras de Arteaga enviaban al mismo tiempo un mensaje a los industriales, planteando que estos deberían realizar importantes transformaciones, adaptándose a un régimen de mayor competencia y, con miras a aquel fin, aumentar sus niveles de eficiencia. De esta manera, la dirigencia de la SOFOFA actuaba como un agente de transformación del sector industrial, a la vez que servía de articuladora entre el gobierno y las diversas ramas de la producción fabril. A través de la exposición de una visión autocrítica y de un discurso transformador, también pretendía relegitimar la labor industrial en un contexto de crecientes cuestionamientos en el ámbito de la discusión sobre política económica. Estas críticas generalmente hacían alusión a las tendencias monopólicas y la falta de eficiencia que habría evidenciado la industria chilena en un contexto de prolongada protección.

"Los industriales, conscientes de la grave responsabilidad que nos incumbe por haber salido de nuestras filas quien rige hoy los destinos de Chile, procuraremos superarnos para estar a tono con los desafíos y exigencias de nuestro destino [...] Sabemos, como ya lo hemos expresado en otras ocasiones, que estamos mal dotados para la lucha económica, como consecuencia de nuestro ancestro de hombres de guerra, de aventuras e ideales. Ello muchas veces nos desplaza del campo económico por elementos extranjeros poseedores de mejores 
atributos para esa lucha y de quienes solo muy lentamente aprenderemos lo que nos falta. De ahí la tendencia creciente de los chilenos a solicitar del Estado apoyo y franquicias que vengan a suplir su carencia de características combativas para el esfuerzo económico. El peligro de que caigamos a impulso de esta tendencia en una mayor intervención estatal se ha ido acrecentando en los últimos años y solo ahora, ante el gobierno del excelentísimo señor Alessandri, podemos confiar en una rectificación de rumbos que reavive nuestro espíritu". (El Mercurio, 22-XI-1958: 21)

Los recién mencionados planteamientos de Arteaga se encontraban en clara sintonía con las orientaciones políticas que planteaba el nuevo gobierno, que pretendía implantar un proyecto de estabilización económica (FfrenchDavis, 1970: 41). Con dicho fin, la administración entrante se aprontaba a contener las demandas sociales, "lidiando con las posibles protestas populares, las que a su vez inducían a los partidos" a "suspender su apoyo" a las medidas que "implicaran ajustes de tarifas de servicios públicos y represión salarial" (Cavarozzi, 2017: 126). De esta manera, pretendía evitar repetir el fracaso de las políticas estabilizadoras que habían tenido lugar durante las administraciones de González Videla e Ibáñez. ${ }^{5}$

En esta tónica, la administración Alessandri apuntó al reemplazo de los cuadros técnicos de la CORFO. El grupo de técnicos que había manejado la agencia de fomento desde su creación, varios de los cuales habían ejercido funciones públicas con anterioridad, incluso desde el periodo de la dictadura de Ibáñez, fueron removidos de sus cargos. Pierre Lehman, empresario de la construcción, asumió la Vicepresidencia de CORFO y procedió a reemplazar a los gerentes de la institución (Cavarozzi, 2017: 76), instalando en ella a miembros de la elite empresarial privada (Montero, 1997: 102). De este modo, se produjo un proceso de "desautonomización relativa del Estado" respecto de las élites empresariales (Cavarozzi, 1975: 395). Esta tendencia no se redujo a la CORFO, sino que se extendió a otras agencias estatales, donde se produjo una "ola de reemplazos masivos", e incluso a instituciones como el Banco Central (Silva, 2010: 123). En general, la tendencia en dichos ámbitos fue a la supresión de los "especialistas de carrera y los políticos" (Montero, 1997:102). La salida de gran parte de los cuadros técnicos autónomos y de funcionarios con claras vinculaciones políticas, fue seguida por la

Cabe mencionar cómo la experiencia del fracaso de las políticas de ajuste emprendidas cuando Jorge Alessandri fue ministro de Hacienda, bajo el Gobierno de Gabriel González Videla, entre agosto de 1947 y febrero de 1950, reforzó en él sus afanes de autonomizar a la presidencia de las demandas sociales y su apoyo por parte de los partidos políticos. Sobre este periodo, y en general las concepciones políticas de Alessandri, véase Arancibia et al. (1996) y Silva Encina (1985). 
entrada de miembros de la Sociedad de Fomento Fabril en altos puestos de la administración pública. Así, las subsecretarías de Economía, Transportes y Minería fueron asumidas, respectivamente por Luis Marty, Patricio Huneeus y Jorge Fontaine, todos ellos miembros de la Sociedad (Correa, 2005: 223). ${ }^{6}$

La CORFO mantuvo su rol planificador, e incluso lo vio reforzado cuando en 1960 se fortalecieron sus "poderes de coordinación del sector público". Sin embargo, reorientó algunos de sus roles, especialmente en el ámbito productivo. Marcando una diferencia con las tendencias que venían teniendo lugar desde la década de 1940, el nuevo gobierno cambió las orientaciones de la CORFO, reforzando su rol crediticio y de fomento en detrimento de su participación directa en la producción (Ortega et al., 1989: 155).7

Por lo demás, con el fin de evitar los efectos recesivos que podría acarrear la política de estabilización monetaria, el gobierno pasaría a fomentar un agresivo plan de obras públicas y construcción de viviendas, lo que facilitaría una reactivación de las industrias que fabricaban bienes para dichos rubros, a la vez que permitiría paliar los problemas del desempleo (Correa, 2005: 225).

Como puede observarse, tanto los planteamientos programáticos como las políticas económicas iniciales y las tendencias en el reclutamiento de cuadros técnicos y directivos estatales del gobierno de Alessandri coincidían, en gran medida, con las demandas que los industriales venían planteando desde inicios de la década de 1950. Estas últimas se enmarcaban en un incipiente programa de política económica que habían desarrollado ante la crisis del modelo de desarrollo hacia adentro y la incertidumbre y potencial

6 El conocimiento experiencial y los vínculos personales del nuevo presidente jugaron un importante rol en el criterio de selección del equipo económico de la presidencia. Como ha señalado Verónica Montecinos, "Alessandri escogió su equipo de asesores económicos principalmente de entre empresarios prestigiosos e ingenieros apolíticos" (Montecinos, 1998: 429). De hecho, el involucramiento directo y cotidiano del presidente en la gestión económica se basaba en gran parte en la confianza que este poseía en sus propias habilidades como administrador, proveniente del sector privado. Esta situación habría generado un "patrón de comportamiento patrimonialista", que marcaría su gestión (Montecinos, 1998: 43).

7 A mediados de diciembre de 1958, en un foro organizado por el Instituto de Ingenieros, se realizó un análisis de la labor de CORFO en sus veinte años de existencia. En dicha ocasión, Luis Adduard, gerente de CORFO que aún no había sido removido por la administración Alessandri, junto con los ex vicepresidentes de CORFO, Mario Sarquis, Germán Picó Cañas, Guillermo del Pedregal y Francisco Cuevas Mackenna, expusieron sobre la historia y los desafíos de la corporación. Varios de los expositores, especialmente Adduard, realizaron una defensa de la gestión de la CORFO ante las críticas que se volvían poderosas en ese momento. Con todo, no es de extrañar que uno de los organizadores del foro, y por ende interesado en poner en debate el rol de la agencia estatal, haya sido Ernesto Ayala Oliva, presidente del Instituto de Ingenieros y uno de los miembros más relevantes del grupo que desde mediados de los 50 se había vuelto hegemónico en la SOFOFA (Panorama Económico, |-1959:17-47). 
amenaza que significó la irrupción de la experiencia ibañista (Fernández y Goldflam, 2016). ${ }^{8}$ Así, el gobierno y la directiva de la SOFOFA convergían en el ya mencionado ideal de "empresa privada en libre competencia", que implicaba la retirada del Estado de la producción directa, la disminución de controles estatales, a la vez que la mantención de una política estatal de fomento a través de créditos a los privados y dinamización industrial vía una mayor inversión del Estado en obras públicas. Al mismo tiempo, compartían un ideal administrativo, el que podríamos denominar como "tecnocrático corporativo empresarial". 9

Durante el periodo que estudiamos, la Sociedad de Fomento Fabril fue dirigida por el un sector reformista del empresariado que era crítico del modo en que se habían desenvuelto las relaciones entre el Estado y la empresa privada bajo el modelo nacional-desarrollista. Gran parte del grupo dirigente de la SOFOFA, que tomó el control de la Sociedad de 1955, se encontraba vinculado a la Asociación de Industriales Metalúrgicos de Chile (ASIMET). ${ }^{10}$ Cabe señalar los importantes vínculos personales que unían a dicho grupo dirigente de la SOFOFA con Jorge Alessandri. Ernesto Ayala había reemplazo a Jorge Alessandri en la conducción de la Confederación de la Producción y el Comercio cuando éste asumió la Presidencia de la República en 1958. En efecto, Eugenio Heiremans había tenido una breve militancia en el Partido Liberal y era cercano al "clan" Alessandri, tanto así que en las elecciones de 1958 había estado a cargo del "sector independiente" de la campaña presidencial de Arturo Matte Larraín, candidato de liberales y conservadores y yerno de Arturo y cuñado de Jorge

8 La relación entre los empresarios industriales y el Estado había sido estrecha desde fines de la década de 1930, cuando el Estado promovió explícitamente políticas de documento e industrialización. Autores como Petras (1969: 50) llegaron a calificar los niveles de protección e intervencionismo estatal proindustrial como un "socialismo para los ricos". Al respecto véase López Bravo (2017: 28), quien sostiene que, a inicios de la década de 1950, los gremios empresariales, y especialmente la SOFOFA, "experimentaron una fase de "transición que las empujó" a rearticular sus organizaciones y cuestionar "su colaboración con el modelo de industrialización bajo la supervisión del Estado". Este punto también ha sido abordado por Luis Ortega (2017a: 41 y 46-51), quien ha señalado que, en la primera mitad de la década de 1950, la SOFOFA, liderada por una nueva generación de dirigentes, habría creado "nuevas líneas estratégicas" con el fin de enfrentar un escenario cada vez más adverso. En dichas transformaciones habrían colaborado las redes internacionales, siendo estas reforzadas por los vínculos con Estados Unidos a través de programas de cooperación, especialmente el Punto IV. Estos nuevos vínculos habrían sido parte de una "ofensiva monetarista" que pretendía frenar las amenazas de carácter marxista y nacionalista en América Latina. Una panorámica sobre las transformaciones de la SOFOFA en el período puede encontrarse en Ortega (2017b).

$9 \quad$ Este concepto describe una perspectiva tecnocrática que valora la experticia empresarial privada como principal fuente de legitimidad de los cuadros técnicos, y que manifiesta desconfianza de los cuadros técnicos generados y reproducidos de manera autónoma por el Estado (Fernández Abara y Goldflam, 2016).

10 Durante el periodo que estudiamos, la Presidencia de la SOFOFA fue ocupada por Domingo Arteaga Infante entre 1955 y 1959, y por Eugenio Heiremans Despouy entre 1959 y 1962. 
Alessandri. Había sido uno de los organizadores de la campaña senatorial de Jorge Alessandri en 1957 y uno de los principales promotores de su campaña presidencial en 1958 (Heiremans, 2008: 178-181). Por su parte, Ernesto Ayala también era cercano a Alessandri y, de hecho, a petición de este lo reemplazó en la Gerencia de la Compañía Manufacturera de Papeles y Cartones cuando asumió la presidencia (Lizana y Vélez, 2008: 15).

Sin embargo, cabe señalar que, en las directrices de su programa económico, Alessandri pretendía "reducir muchos de los controles que el Estado había utilizado para regular la economía por décadas", especialmente en el ámbito de los "precios, salarios, importaciones y movimientos de comercio internacional" (Stallings, 1978: 81). En este sentido, hubo una liberalización de ciertos aspectos de la economía, lo que se notó en el fin a los controles del comercio exterior, "la autorización de la importación de todo tipo de bienes y la reducción de las tasas de los depósitos de importación". Del mismo modo, y tras una devaluación, se unificó el tipo de cambio (Correa, 2005: 224).

Como ha sintetizado María José Gómez Chamorro (1983: 52-53), el proyecto de Alessandri pretendía, en primer lugar, impulsar a la "industria por medio de la intervención del Estado en la economía a través de una política de estabilización y una política de dinamización". En segundo lugar, "crear un clima de confianza para los inversionistas nacionales y extranjeros", a través de la instauración de "reglas claras y constantes para el comercio exterior y el pago de divisas". Finalmente, en tercer lugar, la apertura "de una economía vigorizada, con una industria modernizada y eficiente, a la competencia internacional".

No es de extrañar que en una actitud que Patricio Silva ha descrito como un "Ilamado al espíritu shumpeteriano", las políticas de Alessandri implicaran un desafío para los empresarios industriales, en cuanto estas apuntaban a que "ellos fueran más competitivos para en un futuro próximo poder eliminar los aranceles proteccionistas" (2010: 125). Así diversos autores, como Marcelo Cavarozzi (1975) o María José Gómez Chamorro (1983), han insistido en que el programa del alessandrismo implicaba un "proyecto de modernización industrial". Gómez sostiene que Alessandri pretendía "liberar a los empresarios de la dependencia del Estado, bajo el supuesto de que esta constituía una verdadera traba al espíritu empresarial escondido en los manufactureros del país" (Gómez Chamorro, 1983: 79)¹1. Esto lo planteó

11 De todas maneras, es necesario señalar que Alessandri, en cuanto presidente, tendió a ser desconfiado de la adopción irrestricta de modelos de política económica, y si bien defendió el ideal de "empresa privada en libre competencia" mantuvo una visión proteccionista al defender con tenacidad el "argumento de Industria naciente". Luis Escobar Cerda, economista estructuralista, militante del Partido Radical y quien fuese ministro de Economía 
Jorge Alessandri en su discurso en la cena de aniversario de los 75 años de la SOFOFA, donde dijo abiertamente que el empresariado debería realizar sacrificios, especialmente en los aspectos vinculados al consumo de bienes suntuarios, para fomentar el ahorro y la inversión. Dicho discurso refleja cómo el proyecto del gobierno implicaba la generación de un cambio radical en las conductas y actitudes económicas del empresariado:

"Las obligaciones que he contraído me imponen la necesidad de reclamar de todos los chilenos la cuota de esfuerzo y sacrificio con que han de contribuir a la realización de esta obra restauradora, y es indudable, que aquellos que han tenido el privilegio de poseer más, sea por razón de su inteligencia, por su capacidad realizadora, o por simple disposición del destino, les corresponderá en esta jornada hacer un aporte mayor que el de los otros. Es también indispensable que un reducido número de afortunados prescinda de muchos artículos de consumo fabricados en el extranjero, aunque ellos sean mejores y más baratos que los nuestros, a fin de que las divisas ahorradas por este medio sean debidamente utilizadas en el mejoramiento de equipos y maquinarias, que, como he señalado, son en su mayor parte anticuados e ineficientes". ${ }^{12}$

Al iniciar su gobierno, Alessandri también fue explícito en sostener que la limitación a las protecciones aduaneras proyectadas requería de un cambio en los patrones de gasto e inversión de los industriales, en pos de la inversión: "La protección aduanera debe tener un límite que obligaría a los empresarios a modificar sus instalaciones, modernizándolas para mantener bajos los costos y poder competir con los productos importados". ${ }^{13}$

\section{La Sociedad de Fomento Fabril como agente de modernización industrial y articuladora con el gobierno}

Cabe preguntarse por los mecanismos utilizados por la dirigencia de la SOFOFA para actuar como articuladora entre el gobierno y los productores fabriles, a la vez que para asumir el rol de agente modernizador del sector industrial.

durante su gobierno, entre los años 1961 y 1963, pone énfasis en dicho aspecto en sus memorias (Escobar Cerda, 1991: 56).

12 Jorge Alessandri: "21-XI-58. Discurso en Soc. Fomento Fabril en el 75 aniversario de su fundación", Texto mecanografiado con notas manuscritas, en Archivo Jorge Alessandri Rodríguez, Sala Medina, Biblioteca Nacional (en adelante, AJAR).

13 Presidencia de la República. Secretaría: "Protección Aduanera (Límite que debe tener)", en la opinión de Alessandri a través de sus discursos (Durante Campaña presidencial y primeros años de gobierno) 1959-1960, Texto mecanografiado con notas manuscritas, en AJAR. 
En primer lugar, hay que mencionar el discurso público asumido por la Directiva de la Sociedad, en el que se evidencian explícitos afanes de apoyar al gobierno a la vez que de llamar a los empresarios industriales a modernizarse y estar preparados para adaptarse a una mayor competencia. Desde un comienzo, la directiva de la SOFOFA demostró sus afanes de apoyar a la administración de Jorge Alessandri, manifestando de manera pública un respaldo a su accionar. En reiteradas formas y tonos, Arteaga se refirió a "nuestra obligación de cooperar con él y su gobierno en bien de la patria" (El Diario Ilustrado, 26-III-1959: 5). Eugenio Heiremans, quien asumió la presidencia de la Sociedad en remplazo de Arteaga, en 1959, planteó que "me complace en forma muy especial dejar público testimonio de la identidad de propósitos que tienen los programas del Excmo. Señor Alessandri con el ideario de nuestra entidad" (El Diario Ilustrado, 3-XI-1959: 8).

Por lo demás, sosteniendo que la administración Alessandri era la oportunidad de "delimitar en definitiva la órbita de acción del Estado en el campo económico", los directivos de la Sociedad enarbolaron un discurso en el que hicieron explícitos llamados a los industriales a desligarse de la dependencia del Estado y de la protección del sector estatal y volverse más competitivos. El propio Arteaga, en la junta ordinaria de socios que tuvo lugar el 25 de marzo de 1950, planteó que veía "con temor que muchos, en nuestras propias filas de la industria, se han habituado en tal forma a la intervención del Estado, que buscan su amparo cada vez que algún peligro se cierne sobre sus empresas" (El Diario llustrado, 26-III-1959: 5).

La posible inserción de Chile en la Asociación Latinoamericana de Libre Comercio también fue señalada como un desafío importante, y como una oportunidad que obligaba a modernizarse. Así se señaló en la Memoria Anual de la Sociedad del año 1959, en la que "la industria nacional requiere como una necesidad imperiosa para su desarrollo el contar con mercados amplios, crecientes y firmes" (Memoria Anual, 1959: 4).

Con el fin de reforzar la identidad en torno a un proyecto modernizador de largo plazo, con implicancias sociales más amplias que el inmediato beneficio individual, la Sociedad, dentro del marco de las actividades de su septuagésimo quinto aniversario, creó y puso en vigencia un Código de Ética. En palabras de Arteaga, el Código no solo apuntaría a "fomentar el crecimiento industrial" sino que también sería la "mejor base para solucionar la crisis moral por la que atravesamos hace años". Las normas planteadas en él apuntaban a dos ámbitos fundamentales. Primero, "la actuación del industrial dentro de su industria, en sus relaciones con su personal y con los otros industriales"; y, segundo, "el industrial frente al público consumidor y la nación entera" (La Tercera de la Hora, 3-XII-1958: 5). 
En esta misma lógica, la SOFOFA solicitó a sus miembros realizar sacrificios, "recomendando a sus asociados posponer sus intereses en pos del bienestar del país" (El Mercurio, 13-VIII-1959: 5). Esto implicaba "evitar las alzas abusivas de precios", en aras de mantener una imagen favorable a la industria en la opinión pública, y colaborar con el programa estabilizador. Ya en enero de 1959 Ernesto Ayala había expresado que "no debía exagerarse ni aprovecharse de la libertad de precios, y que cada uno debía dar el ejemplo de cómo debe operar en esta especial circunstancia, para atender a sus obreros y empleados y al país" (Industria, I-1959: 18). En agosto, la SOFOFA repartió a sus asociados una circular en este sentido (El Mercurio, 13-VIII-1959: 18).

En segundo lugar, se vuelve necesario señalar que el afán mostrado por la Sociedad de convertirse en "Centro de Estudios" y agente de opinión en el debate público, tendencia que venía evidenciándose desde mediados de la década de 1950, permitió que este actuara como órgano legitimador del gobierno ante los industriales y la opinión pública en general, dando cuenta de los efectos positivos de su obra, tanto a través de la Hoja de Información Económica, la revista Industria (VII-1959: 22-23) y las memorias anuales, como a través de la publicación de notas de prensa. En este último aspecto, la difusión de los estudios de la sociedad en órganos de prensa y empresas periodísticas con agendas políticas, hasta cierto punto afines, se volvió relevante para llevar las informaciones del Departamento de Estudios de la Sociedad a un público más amplio. Fueron los casos del diario estatal La Nación; El Diario Ilustrado, periódico del Partido Conservador, y El Mercurio. La difusión de las estadísticas elaboradas por la Sociedad cumplió un importante rol en este aspecto. Estas apuntaban a promover una sensación de confianza entre los industriales y la población en general, enfatizando el mejoramiento de la producción y del empleo, señalando que este se debía en gran parte al clima de confianza generado por la nueva administración. Además, constantemente recalcaban que dichas situaciones se enmarcaban en desafíos de más largo plazo, generados por las deficientes condiciones en que había quedado la economía, especialmente tras la política del gobierno anterior. ${ }^{14}$

En tercer lugar, es necesario referirse a las prácticas políticas utilizadas por la Sociedad para intermediar entre los industriales y el gobierno. De su observación puede colegirse que la Sociedad se convirtió en una instancia negociadora y amortiguadora de algunos de los afectos adversos de la acción

14 Los títulos de las notas publicadas en la prensa afín son representativos de esta tendencia. Por ejemplo "Revelador informe. Mayor demanda de brazos. Crece número de obreros y empleados en las actividades nacionales, disminuyendo los cesantes. Promisorias perspectivas muestra estudio de Fomento Fabril. Mejoran los niveles" (La Nación, 7-I-1959: 1); "Progreso industrial" (La Nación, 20-V-1959: 3); "Fomento Fabril destaca aumento de la producción y ocupación industrial" (El Mercurio, 30-X-1959: 21). 
gubernamental para sectores industriales específicos. En consonancia con el programa y el accionar de la nueva administración, buscó promover soluciones de compromiso que atenuaran los efectos más radicales de las medidas del gobierno, en aras de facilitar la adaptación de las empresas para su implementación en un mediano plazo. Este rol se volvía de suma importancia ante la potencial dificultad de mantener la cohesión de la organización, en un contexto en que las transformaciones que el gobierno realizaba a la política económica removían controles que habían permitido subsistir y asegurar la estabilidad de diversas industrias.

Un ejemplo de este tipo de prácticas puede ser observado en el modo en que la Sociedad asumió las negociaciones entre los empresarios molineros y el gobierno. A fines de diciembre de 1958, el subsecretario Martí envió al presidente de la Sociedad una comunicación poniendo a su directiva en conocimiento de las políticas de la Subsecretaría de Hacienda hacia la industria molinera, señalando que estas apuntaban a la "completa libertad y competencia en dicha actividad", a la vez que consultando la opinión de la Sociedad sobre el tema. Tras haber deliberado el tema con el Consejo Directivo, y contando con la participación de los involucrados a través de la Asociación de Molineros del Centro, el presidente de la Sociedad hizo notar que, si bien se exigía a los industriales molineros entrar en un régimen de libre competencia, el precio de su principal materia prima, el trigo, aún estaba regulado, lo que afectaba sus costos y los sometía a la actuación discrecional del Estado. Sin embargo, en su respuesta, en lugar de oponerse a la liberalización, Arteaga planteaba que era "aconsejable arbitrar de inmediato medidas que procuren que esta actividad se conforme a aquellos principios, consultando una etapa de transición, bien proyectada y reglamentada, que posiblemente no debiese ser superior a un año" y que "para tal efecto, podría estudiarse, desde luego, y en conjunto con las partes afectadas, la reglamentación necesaria para iniciar la sugerida etapa de transición sin daños inútiles" (La Nación, 1-II-1959: 8). La mencionada negociación dejaba en evidencia la fluidez de las relaciones entre el gobierno y la SOFOFA, y una importante coincidencia en objetivos de largo plazo; a la vez que evidenciaba la capacidad de la segunda para actuar como mediadora entre el gobierno y sectores específicos del empresariado. Del mismo modo, la exposición pública de las comunicaciones, en el marco del periódico estatal, es señal de una estrategia que apuntaba a mostrar unidad entre el gobierno y los empresarios. ${ }^{15}$

15 Cabe mencionar cómo diversos sectores del empresariado recurrieron al propio Heiremans para que actuara como negociador en representación de sus demandas ante la presidencia. Al respecto, véase la "Carta de Armando Gellona, Guillermo Aspillaga A., José Said y Domingo Arteaga Garcés e Eugenio Heiremans". Santiago, 27 de junio de 1960, en Fondo Jorge Alessandri Rodríguez, Archivo CIDOC, Universidad Finis Terrae. En la misiva, los productores de ácido sulfúrico demandaban un "trato equitativo" en los aranceles de importación del 
Además del tipo de prácticas recién mencionadas, la directiva de la SOFOFA utilizó algunos de sus usuales mecanismos de acción con el fin de mantener influencia en el gobierno, para los que ahora contaba con mayor receptividad. En este aspecto, se dio continuidad al uso de instancias de persuasión privadas, a través de la comunicación directa con las autoridades y la "colaboración" en los estudios y redacción de proyectos ${ }^{16}$. En algunas ocasiones, los modos de colaboración fueron públicos, como la participación de los miembros de la SOFOFA en la elaboración de los nuevos aranceles aduaneros, instancia en la que promovieron su proyecto de instaurar aranceles con objetivos de fomento y no solo fiscalistas (Gómez Chamorro: 1983: 56, e Industria, V-1959: 13). La Comisión Relacionadora SOFOFA-CORFO mantuvo su trabajo y pasó a tener un rol fundamental en la elaboración del Plan de Desarrollo Industrial, que llevaría a cabo la agencia estatal (Industria, III-1959: 7).

\section{Los tributos para la reconstrucción y el crédito: las primeras divergencias}

María José Gómez (1983: 59) sostiene que el año 1960 marca el inicio de los desacuerdos entre la Sociedad de Fomento Fabril y el gobierno. Coincidimos con la autora en cuanto hemos podido constatar que, en dicho año se hicieron evidentes las primeras críticas de los empresarios industriales a elementos concretos de la política económica del gobierno. Sin embargo, en el periodo no se evidencia un rechazo al proyecto integral de la administración Alessandri por parte de la SOFOFA, la que continuó actuando como transmisora de inquietudes y demandas de sectores específicos del empresariado industrial, a la vez que defendiendo en términos generales el proyecto del gobierno. La actitud de la SOFOFA sirvió para catalizar el descontento de sectores específicos del empresariado, en un marco de mantención de la política de colaboración con el gobierno.

Las transformaciones que comenzaron a evidenciarse en la actitud de distintos sectores del empresariado, pueden entenderse en el contexto de diversas alteraciones que sufrió el desenvolvimiento de la economía en el periodo. Cavarozzi (1975: 379) ha señalado que algunos elementos imponderables, como la baja del precio internacional del cobre y el terremoto que destruyó el sur de Chile en mayo de 1960, disminuyeron la capacidad del

azufre extranjero, que resultaría más barato que el nacional. En dicha ocasión, el presidente de la Sociedad de Fomento Fabril actuó personalmente como intermediario ante Jorge Alessandri, elevando su demanda al presidente.

16 En efecto, el propio Eugenio Heiremans planteó que diversos asesores trabajaban de manera anónima en las comisiones de la SOFOFA, para "proporcionarle al gobierno material informativo" (El Diario llustrado, 3-XI-1959: 8). 
gobierno para destinar fondos a la inversión en aumento de la capacidad productiva del país. ${ }^{17}$ Si bien entre 1958 y 1960 el precio mundial del cobre había tendido al alza, entre los años 1960 y 1961 descendió de 706,59 a 659, 63 dólares por tonelada métrica (Braun et al., 2000: 130). Por lo demás, la misma progresión del programa económico de Alessandri implicaba la aparición de nuevos desafíos y dificultades para los empresarios. Como ha planteado María José Gómez Chamorro (1983: 59-61), hacia 1960 la política de liberalización del comercio exterior fue profundizada y sus efectos se hicieron más notorios. En efecto, mientras las exportaciones se mantuvieron relativamente estables, entre 1959 y 1961 las importaciones aumentaron de 426,20 a 619,60 millones de dólares en el mismo periodo (Braun et al., 2000: 155). Al mismo tiempo, la política de estabilización había redundado en un incremento del costo del crédito.

En este escenario, la SOFOFA expresó algunas divergencias en torno a las políticas de reconstrucción emprendidas por el gobierno tras el terremoto que afectó la zona sur de Chile en mayo de 1960. Específicamente, los reclamos de la Sociedad se hicieron patentes respecto al aumento de la carga tributaria para las industrias que traía aparejada la reconstrucción. Aunque la Sociedad se movilizó en ayuda de las zonas afectadas, manifestó algunos reparos respecto del modo en que se repartían los costos de la reconstrucción, indicando que, después de los gastos en que habrían tenido que incurrir para apoyar las políticas de estabilización, los industriales no se encontraban en condiciones de asumir nuevos sacrificios. Así, hicieron llamados a que hubiera un "equilibrado reparto" entre "el aporte económico interno y la obtención de créditos externos" y señalaron que las industrias no se encontraban en condiciones de soportar una mayor carga tributaria, advirtiendo que "la posibilidad de fondos en el país está limitada por la efectiva capacidad de tributación, hoy día cerca de la saturación" (El Mercurio, 16-VII-1960: 3).

La actitud de la Sociedad generó roces con el gobierno, los que se hicieron notar, de manera indirecta, a través de la prensa. El diario La Nación, criticó de manera sutil la actitud que tomó la Sociedad, señalando que esta no habría sido "lo suficientemente explícita en lo que se refiere a la cuota de sacrificios que la actividad manufacturera debe tomar en esta etapa". Al respecto, planteaban que la actitud de la Sociedad podría ser utilizada de manera demagógica por la oposición "para su incansable labor de agitación pública". Esto, en cuanto "dichos sectores señalaban constantemente que el mayor costo financiero" de la reconstrucción, recaía sobre los "sectores más pobres" (La Nación, 16-VII-1960: 3).

17 Sobre el terremoto de 1960, véase el reciente libro de Silva y Riquelme (2018). 
En la situación recién mencionada, la Sociedad opuso resistencia a una política del gobierno, aunque de manera ponderada. Sin embargo, la actitud asumida por la SOFOFA era más flexible y negociadora que la planteada por otras instancias gremiales más específicas del empresariado industrial. Fue el caso de la Asociación de Industriales de Valparaíso y Aconcagua, ASIVA, la que se dirigió "de manera dura y contundente contra los impuestos establecidos en apoyo a la reconstrucción en el sur". Si bien los empresarios de ASIVA, que se encontraban representados al interior de la SOFOFA, no adoptaron una postura opositora al gobierno, si vieron con desconfianza la falta de independencia que mostraba la SOFOFA respecto de éste (La Libertad, 2-VIII-1960: 3). En este punto, se hacían notar las primeras divergencias al interior de los empresarios industriales sobre la relación de sus instancias gremiales con el gobierno.

Con todo, el problema que comenzó a notarse en el año 60, que se volvería más evidente el año siguiente, y se terminaría por convertir en un tema constante de tensión entre el gobierno y la Sociedad, tenía que ver con la política crediticia para la industria. Dicho tópico no era nuevo, y ya se había hecho presente en el marco de políticas económicas estabilizadoras. ${ }^{18}$ Como ha señalado María José Gómez (1983: 61), desde inicios del gobierno de Alessandri los industriales solicitaban una mayor disponibilidad de créditos con el fin de paliar los crecientes costos y demanda de circulante generados por el proceso inflacionario. Dichas quejas tuvieron continuidad hacia 1960 cuando, producto de las medidas estabilizadoras, aumentaron los costos del crédito (Gómez, 1983: 61-62). En el marco de la Junta General de Socios de abril de 1960, el propio Heiremanss, planteó que:

"Se trata señores, de un crédito caro. Comprendemos que este fenómeno responde a un régimen transitorio que tienta a regular el uso indiscriminado de él. Pero una vez alcanzado, será fundamental modificar rumbos en este sentido y poner a disposición de los productores un crédito a precio razonable. Así como también creemos que podremos llevar el crédito a corto plazo a realizar su verdadera función". (Industria, III-1960: 16)

Sin embargo, la visión gradualista planteada por Heiremans puede ser contrastada con otros antecedentes que señalan que, al interior del empresariado, existían sectores altamente descontentos con la falta de disponibilidad de créditos, los que demandaban medidas inmediatas y esperaban un accionar más enérgico de parte de la Sociedad. Marcelo Cavarozzi (1975: 377) ha señalado que, en las reuniones del Consejo Directivo de la SOFOFA, diversos

18 Fue el caso de la actuación de la Sociedad de Fomento Fabril durante el programa estabilizador de la Misión Klein-Saks, durante el gobierno anterior. 
personeros, entre ellos Fernando Smits y Hernán Elgueta, manifestaron su preocupación por los signos de estancamiento que estaría denotando el proceso de reactivación económica. En opinión de los sectores críticos, el gobierno debería tomar medidas destinadas a mantener activada la economía y prevenir su nuevo estancamiento. Aun cuando las publicaciones de la Sociedad y la prensa afín al gobierno no dieron cuenta de la existencia de sectores críticos al interior, sí lo hizo la prensa opositora. En abril de 1960, el economista Aníbal Pinto Santa Cruz señalaba que las cifras mostradas por la propia Sociedad no podían ser interpretadas como un signo de crecimiento, tal como hacía su directiva. Al respecto, planteaba que existía descontento entre los industriales, el que no estaría siendo encarado por la dirigencia de la SOFOFA, y que este se debería a que la política monetaria y crediticia del gobierno estaría teniendo efectos restrictivos sobre la economía (Las Noticias de Última Hora, 23-IV-1960: 2).

"El presidente de Fomento Fabril patinó raudamente en el hielo delgado de la política monetaria y crediticia y no se atrevió a decir lo que los industriales piensan: que la política de los juglares financieros del gobierno ha "secado" el mercado financiero de capitales de todos los recursos que podrían "alimentar" una expansión industrial si las condiciones fueran más propicias". (Las Noticias de Última Hora, 23-IV-1960: 2)

En julio del mismo año, el diario La Libertad dio cuenta de cómo en las bases de la SOFOFA se estaban generando críticas a la política crediticia del Gobierno:

"La prensa ha informado del foro que se realizó la semana pasada en la Sociedad de Fomento Fabril con ocasión de las serias quejas que diversos productores han venido señalando a la política económica del gobierno. En dicho foro se analizó a fondo la situación del crédito bancario que es absolutamente caro y escaso y los efectos que en él ha producido la existencia de bonos fiscales que generan utilidades fabulosas con lo cual se desvían los escasos recursos privados a operaciones comerciales que no tienen carácter normal o de fomento". (La Libertad, 21-VII-1960: 3)

Sin embargo, el accionar de la Sociedad no se limitó a reclamar por la falta de crédito, sino también a plantear posibles soluciones a este problema. En marzo de 1961 la Sociedad presentó al gobierno proyectos específicos para aumentar los créditos y descentralizar sus canales de otorgamiento. El Consejo de la Sociedad aprobó un memorándum para ser sometido a consideración del gobierno. En dicho documento recalcaban la necesidad de aumentar los créditos a mediano plazo para fomento de la producción. Junto con ello, los industriales señalaban que debían ampliarse los fines a los cuales estos se encontraban destinados. Así, sostenían que: 
"Los préstamos deben destinarse a satisfacer todas las necesidades que representen un mejoramiento o aumento de la producción no sólo a través de nuevas inversiones o ampliaciones, sino que también y en forma especial para recuperación de los capitales invertidos en los últimos años en el activo fijo que, a causa del régimen de inflación, han sustraído sumas importantes a los capitales de trabajo". (El Diario Ilustrado, 17-III-1961: 2)

La Sociedad reconocía como "inobjetable" el "derecho "del "gobierno para orientar los créditos con un plan" (El Mercurio, 22-III-1961: 21). Sin embargo, planteaban que la CORFO podría liberarse de la administración de dichos créditos, entregando "a los bancos comerciales las funciones de calificación de los créditos y su correcta aplicación" (El Diario Ilustrado, 18-III-1961: 3). En una tónica similar, en abril del mismo año la Sociedad demandó condiciones equitativas para la industria, respecto a otras ramas de la economía, en la colocación de créditos estatales (Gómez Chamorro, 1983: 66). De esta manera, la SOFOFA pretendía aumentar el crédito estatal y la participación de la industria en aquel, a la vez que autonomizar su administración en instituciones privadas en las que tendría mayor nivel de incidencia. Este último se veía facilitado especialmente por las tendencias a la concentración que presentaba la economía chilena, en la que los grupos económicos, nucleados principalmente en torno a bancos, mantenían intereses y vínculos con los más diversos sectores productivos, incluido el industrial (Lagos Escobar, 1962).

\section{La Convención Nacional de Industrias de 1961 y los últimos intentos de articulación con el gobierno}

Pese a las críticas recién mencionadas, la directiva de la Sociedad continuó defendiendo en términos globales el proyecto del gobierno, tanto entre sus socios como ante la opinión pública. En este sentido, se realizaron instancias de colaboración técnica y de discusión de asuntos vinculados a la política económica con agencias Gubernamentales. En enero de 1961 la SOFOFA inauguró una serie de jornadas de trabajo, a realizar en conjunto con la CORFO, destinadas a "analizar los principales problemas que afectan a la industria nacional". Los temas centrales abordados en dichas jornadas correspondieron al "régimen tributario" y los "sistemas de amortización"; la "legislación social"; el "sistema crediticio"; la "promoción, transporte y comunicaciones"; los "seguros" y la "normalización y sello de calidad"; la "energía" y los "combustibles"; la "preparación de mano de obra calificada" y el entrenamiento de ejecutivos" (La Nación, 12-I-1961: 3). Como puede observarse, el temario de las jornadas apuntaba a reforzar el proceso modernizador de la industria, como respuesta un proyecto del gobierno. Por lo 
demás, la instancia sirvió para dar tribuna al equipo económico del gobierno en defensa de su programa. Así, en dichas jornadas, el ministro de Economía, Julio Philippi, sostuvo que:

"Es conveniente destacar las perspectivas que nos abren las nuevas tendencias de la economía internacional. Ya no debemos planear en función principal de nuestros mercados internos, si no que nos vemos en la necesidad, si queremos marchar con el ritmo acelerado de las demás naciones, de planificar y desarrollar nuestra economía en vista a grandes zonas de libre comercio, para llegar a una complementación e integración crecientes de mercados y fuerzas productoras". (La Nación, 12-I-1961: 3) $)^{19}$

La Sociedad de Fomento Fabril mantuvo su defensa de la política económica del gobierno. Así, a inicios de junio de 1961, en el marco de la asamblea general de ASIVA -instancia en que anteriormente se habían presentado críticas al gobierno-, Ernesto Ayala, a nombre de la SOFOFA, señaló que:

"Podemos considerar a Chile como un enfermo que fue recibido por los actuales médicos (léase el actual Gobierno) en estado muy grave, casi comatoso. Pero la receta (de la estabilización) ha estado operando con resultado favorable. Y hoy, a poco más de dos años de tratamiento, el enfermo sigue mejorando, aunque su estado siempre es delicado". (Vea, 10-VI-1961: 9)

Sin embargo, la principal acción destinada a apoyar la política modernizadora industrial y las políticas del Gobierno fue la Cuarta Convención Nacional de la Industria, realizada entre los días 16 y 18 de junio en Viña del Mar. Según informó Eugenio Heiremans a la prensa, el temario de la Convención apuntaría a abordar los siguientes tópicos:

"Determinar como a afecta la industria a la nueva mentalidad económica que vive el país; estudio y análisis del régimen en que opera la industria; dar a conocer los problemas y las soluciones que requiere la industria; promover la unión de los empresarios; preparar y orientar la actividad manufacturera, y constituir el punto de partida para una gran campaña publicitaria en favor de la industria". (El Diario Ilustrado, 8-VI-1961: 8)

Como puede colegirse de la lectura del temario, mediante la Convención la Sociedad de Fomento Fabril pretendía dar señales de autocrítica constructiva,

19 Sobre la intervención de Julio Philippi Izquierdo en la Convención y en cómo esta fue una exposición de los principales planteamientos del gobierno, véase Millar (2005: 24). 
a la vez que publicitar su disposición para emprender los nuevos desafíos que implicaría la creciente competencia económica. Los directivos de la SOFOFA fueron explícitos en señalar que, a través del evento, pretendían posicionar a la Sociedad ante una opinión pública que consideraba adversa (El Mercurio, 14-VI-1961: 27). En una entrevista a El Mercurio, el vicepresidente de la Sociedad Arturo Aldunate Philips, vicepresidente de la Sociedad de Fomento Fabril, señaló que:

"Es indudable que para el público debe ser extraño un temario tan inusitado, ya que lo común es que en este tipo de convenciones lo asuntos sean tratado en un nivel técnico, fuera del alcance de la colectividad. Que la propia industria se atreva a preguntar por qué son caros los productos nacionales, por qué sucede esto o lo otro, es ya algo nuevo. Y esta novedad la hemos buscado deliberadamente". (EI Mercurio, 14-VI-1961: 27)

La participación de representantes del gobierno en el evento, cuyo discurso se mantuvo en una tónica similar a la de la dirigencia empresarial, reforzó el afán de esta última de demostrar señales de apoyo al gobierno. Entre las principales autoridades que participaron como oradores en el encuentro cabe mencionar a Humberto Díaz, gerente general de la CORFO; Julio Philippi, ministro de Economía, y Eduardo Figueroa, Ministro de Hacienda (Industria, V y VI-1961: 37 y 65). El propio presidente Alessandri envió una carta al presidente de la Sociedad, para ser leída en la convención, en la que felicitaba a los industriales por su "decidida contribución" a la "política de estabilización del Gobierno", a la vez que hacía un llamado a no debilitar dichos afanes, pues "cualquier vacilación en la política económica", terminaría por conducir "fatalmente al país a renovar en proporción aún mucho mayor la catastrófica etapa de la época inflacionaria" (Industria, V y VI-1961: 16).

Sin embargo, el mensaje que se pretendía enviar a través de la convención no solo apuntaba a la opinión pública general, sino que también a los sectores del empresariado que habían manifestado críticas al gobierno. De hecho, el temario no dio espacio para estructurar críticas fundamentales a las orientaciones gubernamentales. Incluso la prensa opositora señaló que la convención habría silenciado las voces disidentes del empresariado, señalando el creciente temor que habría entre los empresarios industriales a la apertura económica (El Clarín, 20-VI-1961: 3).

Con todo, en las discusiones hubo instancias en que se produjeron críticas a la política gubernamental. Específicamente, sectores vinculados a la Industria textil y del plástico manifestaron su disconformidad con las políticas de fomento industrial, de las que se sentían discriminados por las orientaciones gubernamentales. 


\begin{abstract}
"Intervinieron los industriales plásticos y los textiles. Los primeros, que han sido injustamente tildados como "las ovejas negras de la industria", expresaron que habían nacido y crecido y que eran auxiliares indispensables de las demás industrias y que sin ellos no había vida civilizada (botones, juguetes, alambres, aparatos telefónicos, peinetas, envases, etc.) y que sin embargo no habían recibido ayuda de la CORFO ni eran considerados en el Plan Decenal. Por su parte, los textiles también reclamaron por haber sido dejados al margen del plan decenal. Dijeron que eran como "lo parientes pobres" de la industria y que "la CORFO parece que se olvidaba que la gente tiene que vestirse". (Vea, 22-VI-1961: 13)
\end{abstract}

De esta manera comenzaban a hacerse explícitas las fisuras al interior del empresariado en torno a la conducción de la SOFOFA y sus vínculos con el gobierno. Si bien las críticas apuntaban a un elemento específico de la política económica gubernamental, estas fueron hechas en una instancia pública, a la vez que destinadas a reforzar el compromiso de los industriales con el proyecto. Por lo demás, la actitud de los sectores del empresariado recién mencionados, en especial de los textiles, prefigura la actitud que tuvieron en los meses siguientes. En efecto, como ha señalado Marcelo Cavarozzi (1975: 393), gracias a las entrevistas que realizó a informantes clave y a su análisis de las actas del Consejo directivo de la SOFOFA, al interior de la Sociedad se fueron constituyendo facciones que mantenían una actitud discordante para con la directiva de la Sociedad. Por un lado, un grupo liderado por Julio del Río, que era partidario de que la Sociedad adoptara una postura pragmática ante la política económica, aunque estaba dispuesto a contemporizar con la facción liderada por Arteaga, Ayala y Heiremanss. Por otra parte, un grupo vinculado a los empresarios textiles, liderado principalmente por Yarur y Valech, comenzó a discrepar abiertamente de las políticas del gobierno y promovió el uso de "tácticas más duras" hacia este (Cavarozzi, 1975: 394).

\title{
El quiebre de la Sociedad de Fomento Fabril y la caída del sector modernizador
}

Como habíamos señalado, los desafíos crecientes generados por la implementación del programa gubernamental y las dificultades económicas derivadas del terremoto de 1960 y del precio internacional del cobre, crearon un escenario complejo que contribuyó a agudizar el malestar en diversos sectores del empresariado. Sin embargo, la situación económica se volvió aún más desfavorable para el proyecto gubernamental. Según ha señalado Sofía Correa (2005), "se estaba generando un profundo déficit fiscal y de la balanza de pagos". La esperada inversión extranjera, factor fundamental para la dinamización de la economía en el proyecto alessandrista, no llegó en los 
niveles suficientes y la movilización social generaba temor en el empresariado (Stallings, 1978: 82-84). Por lo demás, el apoyo parlamentario al gobierno entró en crisis, los partidos Liberal y Conservador, soportes de Alessandri en el Congreso, no obtuvieron un número de escaños suficientes para asegurar la capacidad del gobierno de ejercer el poder de veto en el proceso legislativo (Correa, 2005: 228-230), lo que ponía en riesgo su capacidad de gobernar. Alessandri debió instaurar un gabinete con representantes de partidos políticos, incluyendo a miembros del Partido Radical, el que recientemente, en su XXI Convención Nacional, había adherido a un programa de profundas reformas estructurales (Gómez, 2003). En octubre de 1961 los reajustes anuales de salarios fueron igualados a la inflación, y en diciembre del mismo año una "crisis financiera provocada por la escasez de divisas" hizo que se "suspendieran las operaciones del mercado de divisas", además de "suprimir el cambio único" (Correa, 2005: 231).

Fue en este escenario que la postura de la directiva de la SOFOFA se volvió insostenible. Durante 1961 esta había logrado contener el descontento de importantes sectores del empresariado y actuar como elemento "amortiguador" (Cavarozzi, 1975: 392) entre ellos y el gobierno. Sin embargo, el derrumbe del diseño de política económica gubernamental, sumado a la vuelta al gobierno de "los políticos" y la mayor receptividad de estos a las demandas del movimiento obrero, los dejó sin un proyecto que defender.

Tras la designación de Luis Escobar Cerda, militante radical, como ministro de Economía, la plana mayor de la Sociedad de Fomento Fabril se reunió con el ministro para, en palabras de Heiremans, dar su "necesario y decidido apoyo al gobierno y al nuevo secretario de Estado" (La Tercera de la Hora, 8-IX-1961: 3). Con todo, el lenguaje y el tono de las declaraciones realizadas a la prensa por los dirigentes de la Sociedad habían cambiado. En efecto, las formas de la relacionarse con la Sociedad del gobierno se volvieron más ásperas y las demandas fueron expresadas con mayor sentido de urgencia y de manera pública. Se hacía evidente que el apoyo de la SOFOFA al Gobierno no era incondicional, al mismo tiempo que reemergían con mayor agresividad las peticiones de créditos y se hacían cuestionamientos públicos a la capacidad de respuesta que tendría la economía nacional al desafío impuesto por la apertura comercial. Así lo planteó la dirigencia de la SOFOFA al nuevo ministro de Economía.

"Le dijimos al ministro que ya estaba bueno que se pusiera en práctica una política realista de créditos a mediano y largo plazo, para lograr un efectivo desarrollo industrial. Además, recalcamos que el gobierno debe conceder a la brevedad créditos especiales para financiar las exportaciones. Todos los países del continente ya los han implementado, sin embargo, aquí no contamos con esos recursos que permitirían 
a nuestros productos competir ventajosamente en el exterior". (La Tercera de la Hora, 8-IX-1961: 3)

El 28 de marzo de 1962, en el Teatro Huérfanos en Santiago, se desarrolló una "asamblea de industriales" organizada por la SOFOFA. Esta tenía como fin dar a conocer el "Plan Publicitario" de la Sociedad. El evento fue calificado por el diario El Mercurio como una "reunión de nuevo cuño", probablemente por su masividad, su apertura y su contenido crítico al gobierno. Si bien el ministro de Economía Luis Escobar Cerda participó del acto, Heiremans planteó importantes críticas al gobierno. Estas fueron especialmente duras en los ámbitos relativos a los aranceles aduaneros, las líneas de crédito y la reforma tributaria. El presidente de la SOFOFA sostuvo que, si bien habían participado por largo tiempo en comisiones e instancias de conversación con el gobierno, estas no habrían surtido efecto deseado y las autoridades se habrían mostrado renuentes a implementar las recomendaciones empresariales. En este sentido, destacaban la necesidad de establecer una campaña dirigida a la opinión pública, antes que actuar a través de instituciones gubernamentales (El Mercurio, 29-II-1962: 12, y La Tercera de la Hora, 29-|||-1962: 4).

El cambio en la actitud de la dirigencia para con el gobierno, sumado al nuevo tono de las declaraciones públicas hacían evidente que la postura del grupo dirigente de la SOFOFA estaba siendo cuestionada. No es de extrañar que los discursos de Heiremans ya hacia inicio de 1962, apelaran en términos generales al anticomunismo y a la responsabilidad de los empresarios con el "mundo libre" como último argumento. Hasta cierto punto, la apelación a argumentos generales y unificadores para la derecha y el mundo empresarial evidenciaba la incapacidad de defender al gobierno en términos económicos y "técnicos". Así, Heiremans planteaba que:

"Nosotros, los industriales, porque somos líderes en el terreno económico, no nos sentimos derrotados de antemano y estamos dispuestos a dar la lucha y sacrificar, nuestro esfuerzo, y nuestras personas, si es preciso, con valentía, para que Chile sea siempre el baluarte extraordinario que siempre ha sido en América Latina y en el mundo entero, de la libertad individual, de la libertad de expresión, de la facultad de elegir libremente, de la facultad de reunirse libremente, de la libertad de trabajo, de la libertad de vivir como hombres dignos y libres, sin esclavitud ni servidumbre de ninguna especie". (El Diario llustrado, 12-IV-1962: 2)

Las pugnas de la Sociedad con el gobierno alcanzaron un punto álgido en el mes de abril de 1962, cuando Heiremans envió una carta a través de la prensa al ministro de Hacienda Luis Mackenna Shiell, en la que cuestionaba abiertamente las políticas económicas gubernamentales. Junto con reclamar por la falta de disponibilidad de crédito. El presidente de la Sociedad sostenía que: 
"La actitud pasiva adoptada por el ministerio a su cargo compromete seriamente nuestro futuro inmediato al haber dañado profundamente nuestro prestigio en el exterior... Hemos demostrado últimamente, en un discurso público, el extraordinario pie de eficiencia y actividad en que se ha venido desenvolviendo la industria nacional, $y$, tememos, con justificada razón, que todo este esfuerzo se esté rompiendo debido al impacto altamente perjudicial de la situación creada en nuestra balanza de pagos y en nuestros compromisos financieros externos". (La Nación, 20-IV-1962: 1)

No solo se estaba evidenciando las dificultades de la SOFOFA con el gobierno, sino que, al mismo tiempo, se hacía visible cómo el descontento de diversos sectores del empresariado industrial, representados en gremios sectoriales, desbordaba la línea oficial de la SOFOFA. A inicios de mayo, la directiva de la Sociedad envió comunicaciones al gobierno con el fin de evidenciar su oposición a la instauración de un impuesto que gravaría la venta de bebidas alcohólicas y gaseosas, la cerveza, y el agua mineral o mineralizada. A mediados del mismo mes, diversas asociaciones gremiales sectoriales que se veían afectadas por la medida enviaron cartas públicas a Heiremans, las que fueron publicadas en diarios de circulación nacional, en las que "apoyaban" sus reclamos ante el gobierno. Fue el caso de la Asociación de Industriales de la Madera, quienes se verían afectados por la disminución de la producción de cajones, y de la Asociación de Fabricantes de Vidrios, Cerámicas y Refractarios, los que verían mermada la producción de botellas y envases (El Mercurio, 19-V-1962: 29, y La Tercera de la Hora, 16-V-1962: 6). De esta manera, la directiva de la Sociedad se veía sobrepasada como instancia negociadora y de representación, a la vez que el descontento de sus bases se hacía visible.

No fue de extrañar que la directiva de la SOFOFA sufriera una renovación. Si bien la mesa directiva de la Sociedad de Fomento Fabril encabezada por Eugenio Heiremans fue reelegida a inicios de mayo de 1962, en julio del mismo año Heiremans y Arturo Aldunate Phillips, presentaron sus renuncias, respectivamente, a la presidencia y la segunda vicepresidencia de la Sociedad. También renunciaron el primer vicepresidente, Ernesto Ayala, y el tesorero, Arturo Kupfer. Si bien se solicitó la reconsideración de la renuncia de Heiremans, este insistió en mantenerla, aduciendo públicamente razones de salud. En el caso de Ayala y Kupfer, sus dimisiones fueron rechazadas por unanimidad. En reemplazo de Heiremans y Aldunate Philips fueron elegidos, "casi por unanimidad" Julio del Río, como presidente, y Víctor Valech, como vicepresidente (El Diario Ilustrado, 9-V-1962: 6, y 19-VI-1962: 1). Como ha señalado Cavarozzi (1975: 393-394), dicha situación evidenciaba el triunfo de una alianza de sectores pragmáticos, partidarios de una línea más independiente del gobierno, y de aquellos proclives a adoptar una política más agresiva hacia este. 


\section{Conclusiones}

Podemos constatar cómo, en el periodo comprendido entre los años 1958 y 1962, la dirigencia de la Sociedad de Fomento Fabril actuó en consonancia con el gobierno, mostrando un alto grado de compromiso con el proyecto de política económica enarbolado por la administración Alessandri. El programa de Alessandri se encontraba vinculado y coincidía con el que los industriales venían desarrollando desde la primera mitad de la década de 1950. Este se caracterizaba por la promoción de una política de estabilización antiinflacionista a la vez que de fomento a través de las obras públicas; la defensa de la libre empresa, entendida como la retirada del Estado de las funciones productivas directas y la instauración de un régimen de competencia en que le reservaba a aquel un rol planificador y de fomento productivo; y la desconfianza hacia los políticos, por su receptividad hacia demandas sociales consideradas "irresponsables" y perjudiciales para la capitalización, y hacia los cuadros tecnocráticos permanentes generados por el Estado por su autonomía. Sostenemos que, en consonancia con el gobierno, la directiva de la Sociedad sí actuó como un agente de modernización industrial. A través de su proceder buscó legitimar el programa de gobierno entre los industriales y transformarse en una instancia articuladora, que canalizara las demandas de los industriales, colaborando en adaptarlas al nuevo escenario, a la vez que ayudar a amortiguar sus efectos más drásticos en aras de su implementación. Por lo demás, la Sociedad de Fomento Fabril sirvió de soporte al programa de gobierno ante la opinión pública, actuando como un entre legitimador de sus políticas.

Los sectores del empresariado industrial, principalmente vinculados a la industria metalmecánica y representados en ASIMET, lideraron dicho proceso y, en general, dieron su apoyo a la directiva, haciéndose parte de un afán de modernización centrado en el ideal de empresa privada. Sin embargo, sectores vinculados a la empresa textil, del plástico, y en general a la producción de bienes de consumo inmediato, demostraron de diversas formas su descontento y tendieron a promover una agenda más cercana a las demandas proteccionistas y de satisfacción de demandas concretas e inmediatas. En este sentido, el conflicto en torno a la modernización industrial y las políticas económicas también era reflejo de los dilemas vividos por el proceso de sustitución de importaciones y de las dificultades vividas por el país para pasar a fases más complejas de este.

La directiva de la Sociedad logró apaciguar las disidencias e incluso evito a evitar su visibilización. Sin embargo, la acumulación de demandas insatisfechas, sumada al fracaso de las medidas estabilizadoras, llevarían a una crisis en las relaciones de la Sociedad con el gobierno, en un proceso de carácter paulatino. En este contexto, la Sociedad de Fomento 
Fabril fue perdiendo su rol mediador entre el gobierno y los empresarios. Poco a poco, sectores dispersos del empresariado industrial comenzaron a formular críticas al proceder gubernamental y a enjuiciar el actuar de la directiva de la Sociedad, condenando su alto grado de compromiso con la administración Alessandri. El golpe final a esta relación de colaboración vino dado por el propio fracaso del programa de gobierno, situación que dejó al sector dirigente de la Sociedad de Fomento Fabril sin un referente externo al que aferrarse y en una debilitada posición interna. Dicho grupo, que había promovido políticas similares a las del gobierno, debió abandonar la promoción del proyecto de modernización económica y perder al liderazgo de la organización, para dar paso a sectores partidarios de la defensa de intereses más inmediatos, vinculados a aumento del crédito y mayor protección estatal.

\section{Referencias bibliográficas}

\section{Fuentes Primarias}

a) Fuentes documentales

Archivo Jorge Alessandri, Sala Medina, Biblioteca Nacional.

Fondo Jorge Alessandri, Archivo CIDOC, Universidad Finis Terrae.

b) Periódicos y revistas

El Clarín, Santiago, 1961.

El Diario llustrado, Santiago, 1958-1962.

El Mercurio, Santiago. 1958-1962.

Industria, Santiago, 1958-1962.

La Nación, Santiago, 1958-1962.

La Tercera de la Hora, Santiago, 1958-1962.

Las Noticias de Última Hora, Santiago, 1958-1960.

Memoria Anual de la Sociedad de Fomento Fabril, Santiago, 1958-1962.

Panorama Económico, Santiago, 1958-1962.

Vea, Santiago, 1961. 


\section{Fuentes Secundarias}

\section{a) Artículos y capítulos de libros}

Beltran, G. J. (2012). "Las prácticas del poder. Discusiones en torno al problema de la acción política empresarial", en Apuntes. Revista de Ciencias Sociales, No70, pp. 69-102.

Fernández Abara, J. y Goldflam, M. (2016). "Hacia la constitución de una economía de mercados jerárquicos: Modernización capitalista y tradicionalismo social en los industriales chilenos (1952-1958)", en Amérique Latine Histoire et Mémoire. Les Cahiers ALHIM, №32, pp. 35-50.

Hoschild, J. L. (2006). "How Ideas Affect Actions", en R. Godin y C. Tilly, Oxford Handbook of Contextual Political Analysis. Oxford: Oxford University Press.

López Bravo, E. (2017). "Del malestar a la amenaza: La Sociedad de Fomento Fabril y el populismo ibañista, 1950-1953", en Izquierdas, №36, pp. 28-54.

Ortega, L. (2015). "Las operaciones ideológicas y políticas en la construcción de un nuevo proyecto económico (y social) para Chile, 1950-1970", en Espacio Regional. Revista de Estudios Sociales, № 11, pp. 67-86.

Ortega, L. (2017a). "Acerca del inicio del proceso de construcción del proyecto monetarista en Chile. Década de 1950. El factor externo", en Contribuciones Científicas y Tecnológicas, Vol. 42, № 1, pp. 41-51.

Ortega L. (2017b). "La nueva SOFOFA, los orígenes del 'gremialismo empresarial' y del 'nuevo liberalismo' en Chile, 1951 y 1958", en M. Llorca-Jaña y D. Barría (editores), Empresas y Empresarios en la Historia de Chile, 1930-2015. Santiago: Editorial Universitaria.

\section{b) Libros}

Arancibia, P., A. Góngora y G. Vial (1996). Jorge Alessandri, 1896-1986. Una biografía. Santiago: Editorial Zig-Zag.

Cavarozzi, M. (2017). Los sótanos de la democracia chilena, 1938-1964. Las esferas de "protección" de los empresarios industriales: la CORFO, la represión a los obreros y la inflación. Santiago: Lom.

Correa, S. (2005). Con las riendas del poder: la derecha chilena en el siglo XX. Santiago: Random House Mondadori.

Escobar Cerda, L. (1991). Mi testimonio. Santiago: Editorial Ver.

Ffrench-Davis, R. (1970). Políticas económicas en Chile. 1952-1970. Santiago: Ediciones Nueva Universidad. 
Heiremans, E. (2008). Mi visión. Cómo empresarios, trabajadores y políticos cambiamos el país. Santiago: El Mercurio-Aguilar.

Lagos Escobar, R. (1962). La concentración del poder económico. Su Teoría. Realidad Chilena. Santiago: Editorial del Pacífico.

Lizana, P. y T. Velez (2008). Ernesto Ayala O. Pensamiento y acción. Santiago: Universidad Autónoma de Chile.

Llorca-Jaña, M. y D. Barría (2017). Empresas y empresarios en la Historia de Chile. 1810-1930. Santiago: Editorial Universitaria.

Millar, R. (2005). Pasión de servicio. Julio Philippi Izquierdo. Santiago: Ediciones Universidad Católica de Chile.

Montecinos, V. (1998). Economists, Politics and the State, Chile 1958-1994. Amsterdam: CEDLA.

Montero, C. (1997). La revolución empresarial chilena. Santiago: CIEPLAN-Dolmen ediciones.

Moulian, T. (2014). Antes del Chile Actual. La década del sesenta. Santiago: Mutante Editores.

Ortega, L., C. Norambuena, J. Pinto, y G. Bravo (1989). Corporación de Fomento de la Producción: 50 años de realizaciones 1939-1989. Santiago: Universidad de Santiago.

Petras, J. F. (1969). Politics and Social Forces in Chilean Development. Berkeley: University of California Press.

Silva, P. (2010). En el nombre de la razón: Tecnócratas y politica en Chile. Santiago: Ediciones Universidad Diego Portales.

Silva, B. y A. Riquelme (2018). Una identidad terremotada. Comunidad y Territorio en el Chile de 1960. Santiago: Ediciones Universidad Alberto Hurtado.

Silva Encina, G. (1985). Jorge Alessandri. Su pensamiento político. Santiago: Editorial Universitaria.

Stallings, B. (1978). Class Conflict and Economic Development in Chile, 19581973. Stanford: Stanford University Press.

c) Tesis

Cavarozzi, M. (1975). The government and the industrial burgeoisie in Chile: 1938-1954. Tesis para optar al grado de doctor. Berkeley: University of California. 
Gómez Muñoz, I. (2003). El Partido Radical durante el Gobierno de Jorge Alessandri, 1958-1964. Memoria Para Optar al Grado de Ciencias Jurídicas y Sociales. Santiago: Facultad de Derecho, Universidad de Chile.

Gómez Chamorro, M. J. (1983). Los empresarios manufactureros ante el proyecto de modernización industrial de Jorge Alessandri. Tesis para optar al título de sociólogo. Santiago: Instituto de Sociología, Pontificia Universidad Católica de Chile. 